\title{
Comparison of biomechanical properties between post penetrating keratoplasty and deep anterior lamellar keratoplasty inkeratoconus patients using ocular response analyser
}

\author{
Nawaz S $S^{1}$, Sofi IA ${ }^{2}$, Prafulla K. Maharana ${ }^{3}$, Shaveta ${ }^{4}$ \\ ${ }^{1}$ Dr Shah Nawaz, Lecturer, Postgraduate Department of Ophthalmology, Government Medical College, Srinagar, ${ }^{2}$ Dr \\ Ishfaq Ahmad Sofi, Registrar, Postgraduate Department of Ophthalmology, Government Medical College, Srinagar, ${ }^{3}$ Dr \\ Prafulla K. Maharana, Assistant Professor, Department Of Ophthalmology, All India Institute Of Medical Sciences \\ Bhopal, Dr Shaveta, Senior resident, Postgraduate Department of Ophthalmology, Lady Hardinge Medical College, New \\ Delhi.
}

Address for correspondence:Dr Shah Nawaz, Email: shaan3638@gmail.com

\begin{abstract}
Introduction: Corneal biomechanics have been studied over recent years. The Ocular Response Analyser (ORA) is the first simple device able to measure the biomechanical properties of the cornea. Deepanterior lamellar keratoplasty (DALK) is considered an alternativeprocedure to penetrating keratoplasty(PK)in advanced keratoconus patients that leaves the host corneal endothelium and Descemet's membrane intact. This provides theadvantage of an absence of potential corneal endothelial rejection. The aim of the study was to compare the biomechanics between the two keratoplasty techniques.Method: This prospective comparative study included 150 eyes of 150 patients.Patients were divided into 3 groups.50 eyes with no previous surgery (Group1), 50 eyes of post PK (Group2) and 50 eyes of post DALK (Group 3) in advanced keratoconus patients were included in the study.Corneal Hysteresis $(\mathrm{CH})$, corneal resistance factor (CRF), Goldmann-correlated intraocular pressure (IOPg)and corneal compensated intraocular pressure (IOPcc) was measured using Reichert ocular response analyser at 1 year follow up. Results: Mean age of the patients in PK group was $24.2 \pm 6.83$ years and $20.95 \pm 6.49$ yrs in DALK group (p value $<0.126$, statistically insignificant). Mean $\mathrm{CH}$ in control group $(10.9 \pm 1.42)$ and DALK group(10.5 \pm 3.79$)$ was significantly higher than PK group $(9.1 \pm 2.36)(\mathrm{p}$ value $<$ 0.01). Mean CRF in control group (10.6 \pm 2.56$)$ and DALK group (10.1 \pm 3.2$)$ was significantly higher than PK group $(8.87 \pm 2.68)$ ( $\mathrm{p}$ value $<0.01)$. However in these groups no statistically significant difference was seen in IOPcc and IOPg. Conclusions: Corneal biomechanical properties in post penetrating keratoplasty and lamellar procedures differ significantly.
\end{abstract}

Keywords: Ocular response analyser, Keratoconus, Deep anterior lamellar keratoplasty, Penetrating Keratoplasty

\section{Introduction}

Keratoconus is a progressive noninflammatory ectatic disease of the cornea. It is one of the most frequent indications for keratoplasty [1]. Any surgical intervention on corneal tissue like keratoplasty results in substantial changes in the tissue structure, and thus, can alter corneal biomechanical properties [2-4], and the cornea may never regain its original mechanical strength after these interventions [5-7].

Manuscript received: $7^{\text {th }}$ Sept 2015

Reviewed: $10^{\text {th }}$ Sept 2015

Author Corrected: $20^{\text {th }}$ Sept 2015

Accepted for Publication: $3^{\text {rd }}$ Oct 2015
Penetrating keratoplasty in the past was the only surgical choice for advanced keratoconus. Because of the complications of penetrating keratoplasty, new techniques were investigated, and deep anterior lamellar keratoplasty is considered an alternative procedure that leaves the host corneal endothelium and Descemet's membrane intact[8]. This provides the advantage of an absence of potential corneal endothelial rejection and preservation of the endothelial cells during the surgery [6]. 
The aim of this study was to compare biomechanical properties of DALK and PK for keratoconus with a control group.This can give us information about the corneal biomechanics after two procedures done for advanced keratoconus.

\section{Material and method}

One hundred fifty eyes of 150 patients were included in this prospective comparative study. The subjects were divided into three groups: group 1 included 50 eyes of 50 patients with no previous ocular surgery (control group); group 2 included 50 eyes of 50 advanced keratoconus patients treated with penetrating keratoplasty; group 3 included 50 eyes of 50 keratoconus patients treated with deep anterior lamellar keratoplasty. Exclusion criteria in the control group were a history of previous corneal surgery, glaucoma, systemic autoimmune disease, diabetes mellitus or dry eye.Informed consent was obtained from all subjects after an explanation of the nature possible consequences of the study.Biomechanical parameters of the cornea, characterizedby corneal hysteresis $(\mathrm{CH})$ and the corneal resistance factor(CRF), were measured with the ORA. The ORA uses arapid air impulse and an advanced electro-optical system torecord two applanation pressure measurements; peak 1 ismoving inward of the cornea, and the other is outward ofthe cornea. The cornea resists the dynamic air puff, causingdelays in the inward and outward applanation events,resulting in two different pressure values. The differencebetween these two pressure values is $\mathrm{CH}$, a new measurementof the cornea to determine its viscoelastic characteristics $[9,10]$. $\mathrm{CH}$ measurement also provides a basis foran additional new parameter, CRF, which appears to be anindicator of the overall resistance of the cornea $[10,11]$. It isa measurement of the cumulative effects of both the viscousand elastic resistance encountered by the air puff while deforming the cornea.All sutures were removed while measuring thecorneal biomechanical properties with ORA. The same person performed all measurements.

\section{Surgical technique}

PK technique: Penetrating keratoplasty was performed with a standard techniqueusing a Barron suction trephine for the host cornea and a Barron punchfor the donor cornea. The chamber was filled with highdensity viscoelastic material before trephination. The range of trephination size in the host cornea was 7.25-8 $\mathrm{mm}$ with a donor graft $0.25-0.50 \mathrm{~mm}$ larger. The oversized donor button was then sutured into the host bed, using 16 interrupted 10-0 nylon sutures (Alcon Laboratories) with buried knots in all eyes [13,14].All operated eyes of both groups received subconjunctival injection of dexamethasone and gentamycin at the end of the procedure.

All eye patches were removed on thefirst day. All eyes of both groups were treated with topical antibiotic drops (Vigamox, moxifloxacinHCl ophthalmic solution, 0.5\%; Alcon Inc., Dallas,TX, USA) q.i.d. A topical steroid such as prednisolone acetateeye drops $1 \%$ (PredForte 1\%; Allergan, Inc., Irvine, CA, USA) wasapplied 4-6 times a day and subsequently tapered over 6-8 weeks.

DALK Technique: Deep anterior lamellar keratoplasty was performedunder regional anesthesia, using diamond knife assisted DALK techniquedescribed by Vajpayee et al [12].

Host Preparation: The surgeries were performed under peribulbar or general anesthesia. A circular mark (7.5 to8.5 $\mathrm{mm}$ in diameter) was made with a disposable trephineblade (Madhu Instruments) whose edges had been stainedwith gentian violet. Intraoperative ultrasonic pachymetry (Micropach, model 200PC, Sonomed) wasperformed on this corneal mark between the 11 o'clock and 1 o'clock positions. A diamond knife set at adepth of $30 \mathrm{~mm}$ less than the intraoperative pachymetry reading was used to make a $2.0 \mathrm{~mm}$ incision at the 11 to12 o'clock position. Medium, curved, fine blade scissors (Cindy Scissors, Bausch \& Lomb) were thenused to extend the incision on either side circumferentially for 360. An open centripetal lamellar dissection was performed using lamellar dissectors. The central stromal disk was then excised, leaving a thin stromal bed.

Donor Preparation: The donor corneo sclera buttonwas placed endothelial side up on a wet polytetrafluoroethylene(Teflon) block. The donor button was punched fromthe endothelial side and was oversized by $0.25 \mathrm{~mm}$. Descemet membrane of the donor lenticule was stripped after staining with $0.1 \mathrm{~mL}$ of trypan blue $0.06 \%$ (Visiblue,Shah\& Shah). The donor lenticule was placed on the hostbed and sutured using 10-0 monofilament nylon. Postoperatively, all patients received prednisolone acetate $1 \%$ eyedrops 4 times a day (Pred Forte 1\%; Allergan, Inc., Irvine, CA, USA) ), moxifloxacin hydrochloride $0.5 \%$ eyedrops 3 times a day(Vigamox, moxifloxacinHCl ophthalmic solution, 0.5\%; Alcon Inc., Dallas,TX, USA), and 
preservative-free artificialtears 4 times a day. The antibiotic eyedrops were continuedfor 2 months, and the topical corticosteroid eyedrops weretapered over 4 months.

Ocular response analyser: The Reichert ORA [9-11] was used to measure corneal biomechanical parameters for all eyes after suture removal at 1 year after of surgery.The patient was seated comfortably on a chair and asked to fixate onthe red blinking light in the device before the device was activated. Then on contact probe of the device released a rapid air puff onto the centreof the cornea and sent a signal to the ORA through an optical sensorwhich measured the deformation of the cornea caused by the air jet. TheORA software utilized the $\mathrm{CH}$ to generate two additional parameters: IOPcc and the CRF. Goldmann correlated intraocular pressure (IOPg) was also provided by the machine. The ORA displayed the biomechanical parameters on the computer monitor attached to the ORA. The average of three good-quality readings for each eye was taken, and those with bad signals or extreme readings were discarded.No cycloplegic eye drops ortopical anaesthetic was administered before the ORA measurements.

Statistical analysis: Statistical analysis was performed using the Student's t-test, and p-value of $<0.05$ was considered statistically significant. Data were expressed as mean, range and standard deviation (SD). Besides descriptive statistics

(Mean \pm standard deviation, frequency, ratio), the one wayANOVA test was used for comparisons.

\section{Results}

Mean patient age (years) was $28.95 \pm 5.8$ in the DALK group, $29.2 \pm 6.83$ in the PK group and $28.36 \pm 5.8$ in the control group (Table 1). No statistically significant differencein mean age was found among the three groups. There was also no statistically significant difference between male and female ratio in the three groups. There was no significant difference between the DALK and PK groups in terms of recipient( $\mathrm{p}=$ value 0.31) and donor (pvalue 0.45) trephine sizes(Table 1). Sutures were removed earlierin the DALK group having all sutures removed before 6 months, compared to none of the PK group till 1 year. All patients achieved their best visual acuity with spectacles. All the parameters were taken at 12 months follow up with sutures out.Significant differences were found between the groups with regard to mean $\mathrm{CH}$ and mean CRF (Table 2).

Corneal hysteresis: The mean postoperative $\mathrm{CH}$ in the DALK group was $10.5 \pm 3.79 \mathrm{mmHg}$ (sutures out) and control group, mean $\mathrm{CH}$ was $10.9 \pm 1.42$.There were no statistically significant difference in mean $\mathrm{CH}$ between the DALK group and the matched controls 12 months postoperatively(p value 0.31 ).

In the PK group, the mean postoperative $\mathrm{CH}$ was $9.1 \pm 2.36$ that was significantly lower than the DALK (p value 0.01 ) and control groups (p value 0.001)at 12 months postoperatively.

Corneal resistance factor: Mean postoperative CRF in the DALK group was $10.1 \pm 3.2 \mathrm{mmH}$ at12 months andthe control group it was $10.6 \pm 2.56$. No statistically significant difference was found between the mean CRF in the DALK and control group 12 months postoperatively(p value 0.48).In the PK group, the mean postoperative CRF was $8.87 \pm$ $2.68 \mathrm{mmHg}$ at 12 monthswhich was significantly lower than both DALK (p value 0.001)and control group (p value $0.001)$.

CCT, IOPg and IOPce : The mean postoperative CCT in the DALK group was $565 \mu \mathrm{m} \pm 10.1$ and $551 \mu \mathrm{m} \pm 13.2 \mu \mathrm{m}$ in the PK group at 12 months postoperatively. In the control group, the mean CCT was $547 \pm 15.43 \mu$ m. No statistically significant difference in CCT was seen in the three groups. The mean IOPg in the DALK group was $12.9 \pm 1.8$ and $13.41 \pm 1.8$ in the PK group at 12 months post operatively. The mean IOPg in the control group was $13.1 \pm 1.4 \mathrm{mmHg}$. No statistically significant difference in IOPg was seen in three groups. In the DALK group, the mean IOPcc was 13.50 \pm 2.1 and $13.8 \pm 3.2$ in the PK group at 12 months postoperatively. In the control group, the mean IOPcc was $13.9 \pm 1.6$ $\mathrm{mmHg}$. No statistically significant difference was seen in the three groups. 
Table 1: Patient demographic data and operative data

\begin{tabular}{|l|l|l|l|l|l|l|}
\hline & Control Group & PK group & DALK group & $\begin{array}{l}\text { DALK vs } \\
\text { PK group }\end{array}$ & $\begin{array}{l}\text { DALK vs } \\
\text { Control } \\
\text { group }\end{array}$ & $\begin{array}{l}\text { PK vs } \\
\text { Control } \\
\text { group }\end{array}$ \\
\hline Age(years) & $28.36 \pm 5.8$ & $29.2 \pm 6.83$ & $28.95 \pm 6.49$ & 0.89 & 0.69 & 0.61 \\
\hline Male & 31 & 28 & 30 & & 0.88 & 0.78 \\
\hline $\begin{array}{l}\text { Female } \\
\text { in mm }\end{array}$ & 19 & 22 & 20 & & 0.80 \\
\hline $\begin{array}{l}\text { Donor diameter } \\
\text { in mm }\end{array}$ & & $\begin{array}{l}7.51 \pm 0.75 \\
(7.25 \pm 8)\end{array}$ & $\begin{array}{l}7.9 \pm 0.21 \\
(7.5-8.5)\end{array}$ & & 0.31 \\
\hline
\end{tabular}

PK- Penetrating keratoplasty, DALK- Deep Anterior Lamellar Keratoplasty

$\mathrm{p}$ value $<0.05$ significant

Table 2: Corneal parameters of the three groups.

\begin{tabular}{|l|l|l|l|l|l|l|}
\hline & $\begin{array}{l}\text { Control } \\
\text { Group }\end{array}$ & PK group & DALK group & $\begin{array}{l}\text { DALK vs PK } \\
\text { group }\end{array}$ & $\begin{array}{l}\text { DALK vs } \\
\text { Control } \\
\text { group }\end{array}$ & $\begin{array}{l}\text { PK vs Control } \\
\text { group }\end{array}$ \\
\hline CH & $10.9 \pm 1.42$ & $9.1 \pm 2.36$ & $10.5 \pm 3.79$ & 0.01 & 0.31 & 0.001 \\
\hline CRF & $10.6 \pm 2.56$ & $8.87 \pm 2.68$ & $10.1 \pm 3.2$ & 0.001 & 0.48 & 0.001 \\
\hline CCT $\mu$ m & $531 \pm 14.1$ & $551 \pm 13.2$ & $565 \pm 10.1$ & 0.85 & 0.74 & 0.69 \\
\hline Keratometry & $43.58 \pm 1.4$ & $46.1 \pm 4.1$ & $45.8 \pm 3.1$ & 0.12 & 0.18 & 0.03 \\
\hline $\begin{array}{l}\text { Spherical } \\
\text { equivalent }\end{array}$ & $-1.5 \pm 1.1$ & $-2.5 \pm 1.9$ & $-2.32 \pm 2.1$ & 0.21 & 0.03 & 0.02 \\
\hline IOPg & $13.1 \pm 1.4$ & $13.41 \pm 1.8$ & $12.9 \pm 1.8$ & 0.45 & 0.68 & 0.74 \\
\hline IOPcc & $13.9 \pm 1.6$ & $13.28 \pm 3.2$ & $13.5 \pm 2.1$ & 0.69 & & 0.72 \\
\hline
\end{tabular}


CH- Corneal hysteresis, CRF- Corneal resisitance factor, CCT- Central corneal thickness, IOPg- Goldmann corrected IOP, IOPcc- Corneal thickness corrected IOP

Keratometry $(\mathbf{k m})$ and spherical equivalent $(\mathrm{SE}): \mathrm{Km}$ and SE values in control group were significantly lower than in DALK and PK group. However, Km and SE values were slightly higher in PK group but was statistically insignificant.

\section{Discussion}

Penetrating keratoplasty has been successfully used in treating advanced keratoconus $[13,14]$. However, in the last few years DALK has been regarded as an alternative in which there is no descemet's involvement[15-17].

DALK has several advantages over penetrating keratoplasty. These are:

1. Less endothelial cell loss.

2. Sutures can be removed earlier.

3. Surgery is extraocular.

4. Rejection of the endothelium was not seen.

5. Steroid treatment can be stopped earlier $[16,18]$.

Our study comparing DALK and PK using ORA showed DALK is superior to PK in attaining biomechanical characteristics more towards normal eyes. Measurements from ORA were taken in normal, postoperative penetrating keratoplasty(PK) and deep anterior lamellar keratoplasty (DALK) done for advanced keratoconus.

The ORA, developed by Reichert Ophthalmic Instruments, was used in this study to evaluate the biomechanical properties of the cornea. Corneal hysteresis represents the viscous damping nature of the cornea; CRF represents the overall resistance of the cornea[19]. Currently ORA is the only method used to measure corneal elasticity[20-23]. Most of the studies have been done on measuring the corneal elasticityin keratoconic eyes and it was found that $\mathrm{CH}$ and $\mathrm{CRF}$ werelower in keratoconic eyes than in healthy eyes [24,25]. Other conditions were ORA was used in different studies were Fuchs dystrophy,high myopia,glaucoma [19], post LASIK eyes [25,26] and post-PTK eyes[27] and it was found that $\mathrm{CH}$ was significantly lower in these conditions. Studies have shown that corneal hysteresis is a new indicator for screening patients for refractive surgeries, as it may help to diagnose form keratoconus, which is an important cause of post LASIK ectasia [28]. Studies were also done to observe the change in corneal hysteresis in keratoconus after treating them with UVA corneal collagen crosslinking. UVA corneal collagen cross linking (CXL) is a safe method forstabilizing the progression of keratoconus [29,30]. Vinciguerraet al., reported that there was no statistically significant difference between $\mathrm{CH}$ and $\mathrm{CRF}$ values beforeand after 1 year of post-crosslinking. Mean $\mathrm{CH}$ and CRFvalues were $9.13 \pm 1.71$ and $9.05 \pm 1.76 \mathrm{mmHg}$ in the preoperative group and $9.27 \pm 1.25$ and $9.01 \pm$ $1.12 \mathrm{mmHg}$ in the 1year postoperative. They concluded that the change in biomechanical factors of the cornea may be lessthan what can be measured by the sensitivity of the ORA,or it might indicate that CXL changed corneal biomechanicsthat cannot be detected by the viscoelastic parameters, $\mathrm{CH}$ and CRF [31]. Another similar study by Gkikiaetal., evaluated the corneal resistance factor after corneal crosslinking for keratoconus. The ORA parameters also in this study showed no significant difference on keratoconus after crosslinking, however significant correlation was found between ORA parameters and Best corrected visual acuity,central corneal thickness, keratometry, astigmatism and residual astigmatism [32].

Jafarinasab et al., compared 45 eyes of 36 patients who had PK surgery with 23 eyes of 21 patients who had DALK surgery. They found that graftbiomechanical properties are similar to those after PK. CHand CRF were measured at $10.09 \pm 2.5$ and $10.13 \pm 2.2 \mathrm{mmHg}$ in the PK group and $9.64 \pm 2.1$ and $9.36 \pm 2.1 \mathrm{mmHg}$ in the DALK group, respectively[33]. In conclusion,they said that biomechanical properties after DALK andPK are similar and provide similar rigidity properties. However, in our study we found that $\mathrm{CH}$ and $\mathrm{CRF}$ werelower in the PK group, which differs from this study.Jafarinasab et al.,however did not mention about the severity of keratoconus, while our study included patients of only advanced keratoconus in both DALK and PK group.

Hosnyet al., comparedthree groups: normal subjects, patients whounderwent penetrating keratoplasty surgery and patients who underwent DALK surgery. ORA was performed 2 months after the surgery for all patients. It was found that the mean $\mathrm{CH}$ and $\mathrm{CRF}$ values were $10.86 \pm 1.36$ and $11.16 \pm 1.5 \mathrm{mmHg}$ in the control group, $9.57 \pm 0.33$ and $9.59 \pm 1.5 \mathrm{mmHg}$ in the PK group, and $10.87 \pm 1.39$ and $11.25 \pm 1.46 \mathrm{mmHg}$ in DALK group, respectively[34]. No statistically 
significant differences between the mean $\mathrm{CH}$ and CRF in the DALK and control groups were found. However, the mean $\mathrm{CH}$ and $\mathrm{CRF}$ in the PKgroup were significantly lower than in the other two groups, similar to our study. However in this study ORA was performed after 2 months only.

Abdelkader reported both mean $\mathrm{CH}$ and mean CRF were significantly lower in PK group (sutures on; 10.1 \pm 1.11 and $9.6 \pm 1.08 \mathrm{mmHg}$ ) than in DALK (sutures out; $12.25 \pm 1.13$ and $12.09 \pm 1.05 \mathrm{mmHg}$ ) and control groups $(12.98 \pm 1.19)$ and $(12.59 \pm 0.94 \mathrm{mmHg})$ at 6 months, respectively $(\mathrm{p}<0.0001)$. After1 year, there was no statistically significant difference in mean $\mathrm{CH}$ and CRFbetween DALK $(12.68 \pm 1.11$ and $12.18 \pm$ $1.11 \mathrm{mmHg}$ ) and PK groups (stillsutures on; $12.36 \pm$ $1.32 \mathrm{mmHg}, \mathrm{p}=0.39$ and $11.83 \pm 1.26 \mathrm{mmHg}, \mathrm{p}=$ 0.33 , respectively)[35)] but in our study both $\mathrm{CH}$ and CRF were lower in PK group.

In this study by Abdelkader ORA parameters in PK group were taken withsuture on, which may be the cause of conflicting results.However, the mean CRF was significantly lower in the PK than the control group ( $\mathrm{p}=0.03$ ). No statistically significant difference in mean $\mathrm{CH}$ or mean CRF was found between DALK and control groups at any time-point, which was similar to our study.

Acar et al.,The $\mathrm{CH}$ and CRF values in PK group were significantly lower than in Control group and DALK $\operatorname{group}(\mathrm{p}=0.001)$. The $\mathrm{CH}$ and $\mathrm{CRF}$ values were similar in group 1 and group3. There was no statistically significant difference between Control group and DALK group [36], which was similar to our study.

\section{Conclusion}

DALK procedure provides better corneal rigidity as compared to $\mathrm{PK}$ in keratoconus patients.

\section{Funding: Nil}

Conflict of interest: None.

Permission of IRB: Yes

\section{References}

1. Rabinowitz YS. Keratoconus (Review).Surv Ophthalmol.1998Jan-Feb;42(4): 297-319.

2. Chihara E, Takahashi H, Okazaki K, Park M, TanitoM.The pre-operative intraocular pressure level predictsthe amount of underestimated intraocular pressureafter LASIK for myopia. $\mathrm{Br} \mathrm{J}$ Ophthalmol 2005Feb;89(2):160-4.doi.10.1136/bjo.2004.048074.

3. Ortiz D, Piñero D, Shabayek MH, ArnalichMontielF,Alió JL. Corneal biomechanical properties in normal,post-laser in situ keratomileusis, and keratoconiceyes.J Cataract Refract Surg 2007 Aug; 33(8): 1371-5. doi.10.1016/j.jcrs.2007.04.021.

4. Davison PF, Glabavy EJ. Connective tissue remodellingin corneal and scleral wounds. Invest Ophthalmol VisSci 1986Oct;27(10):1478-84.

5. Gassett AR, Dohlman CH. The tensile strength ofcorneal wounds.Arch Ophthalmol 1968May;79(5):595-602.

6. Simonsen AH, Andreassen TT, BendixK.The healingstrength of corneal wounds in the human eye.Exp EyeRes 1982Sep;35(3):287-92.

7. Smelser GK, Polack FM, Ozanics V. Persistence ofdonor collagen in corneal transplants. Exp Eye Res 1965Dec;4(4):349-54.

8. Reinhart WJ, Musch DC, Jacobs DS, Lee WB, Kaufman SC,Schtein RM. Deep anterior lamellar keratoplasty as an alternativeto penetrating keratoplasty a report by American Academy ofOphthalmology. Ophthalmology. 2011Jan;118(1):209-18. doi: 10.1016/j.ophtha.2010.11.002.

9. Luce DA. Determining in vivo biomechanical properties of thecornea with an ocular response analyzer. J Cataract Refract Surg.2005Jan; 31(1): 15662.doi:10.1016/j.jcrs.2004.10.044

10. Feizi S, Einollahi B, Yazdani S, Hashemloo A. Graft biomechanicalproperties after penetrating keratoplasty in keratoconus. Cornea. 2012 Aug;31(8):855-8. doi: 10.1097/ICO.0b013e31823f8ce4.

11. Shah S, Laiquzzaman M, Bhojwani R, Mantry S, CunliffeI.Assessment of the biomechanical properties of the cornea withthe ocular response analyzer in normal and keratoconic eyes.Invest Ophthalmol Vis Sci. 2007Jul;48(7):3026-31.doi:10.1167/iovs.04-0694.

12.Vajpayee R, Maharana P, Sharma N. Diamond knife-assisted deep anterior lamellar keratoplasty to 
manage keratoconus. Journal of Cataract and refractive Surgeries.2014Feb;40(2):276-82. doi:

10.1016/j.jcrs.2013.07.047

13. Troutman RC, Lawless MA. Penetrating keratoplasty for keratoconus.Cornea. 1987;6(4):298305.

14. Lim L, Pseudovs K, Coster DJ. Penetrating keratoplasty for keratoconus: visual outcome and success. Ophthalmology.2000Jun;107(6):112531.doi:10.1016/S0161-6420(00)00112-3.

15. Melles GR, Lander F, Rietvelt FJ, Remeijer L, BeekhuisWH,Binder PS. A new surgical technique for deep stromal, anteriorlamellarkeratoplasty.Br J Ophthalmol. 1999Mar;83(3):327-33.

16. Reinhart WJ, Musch DC, Jacobs DS, Lee WB, Kaufman SC,Schtein RM. Deep anterior lamellar keratoplasty as an alternativeto penetrating keratoplasty a report by American Academy ofOphthalmology. Ophthalmology. 2011Jan;118(1):209-18. doi: 10.1016/j.ophtha.2010.11.002.

17. Javadi MA, Feizi S, Yazdani S, Mirbabaee F. Deep anteriorlamellar keratoplasty versus penetrating keratoplasty for keratoconus.A clinical trial. Cornea. 2010Apr;29(4):365-71. doi: 10.1097/ICO.0b013e3181b81b71.

18.Al-Torbak AA, Al-Motowa S, Al-Assiri A, AlKharashiS,Al-Shahwan S, Al-Mezaine H, et al. Deep anterior lamellarkeratoplasty for keratoconus. Cornea. 2006May;25(4):408-12.doi: 10.1097/01.ico.0000220777.70981.46.

19. Shin JY, Choi SJ, Oh JY, Kim MK, Lee JH, Wee WR. Evaluationof corneal biomechanical properties following penetrating keratoplastyusing the ocular response analyzer.Korean J Ophthalmol.2010Jun;24(3):139-42. doi: 10.3341/kjo.2010.24.3.139.

20.Edmund C. Assessment of an elastic model in the pathogenesis ofkeratoconus.ActaOphthalmol. 1987Oct;65(5):545-50.

21. Foster CS, Yamamato GK. Ocular rigidity in keratoconus. Am JOphthalmol. 1978Dec;86(6):802-6.
22.Edmund C. Corneal rigidity and ocular rigidity in normal andkeratoconic eyes. ActaOphthalmol. 1988 Apr;66(2):134-40.

23. Hartstein J, Becker B. Research into the pathogenesis of keratoconus: A new syndrome low ocular rigidity, contact lenses andkeratoconus. Arch Ophthalmol. 1970 Dec;84(6):728-9.

24.Yenerel NM, Kucumen RB, Gorgun E. Changes in corneal biomechanicsin patients with keratoconus after penetrating keratoplasty. Cornea. 2010 Nov;29(11):1247-51. doi: 10.1097/ICO.0b013e3181ca6383.

26. Qazi MA, Sanderson JP, Mahmoud AM, Yoon EY, Robetrs CJ,Pepose JS. Postoperative changes in intraocular pressure andcorneal biomechanical metricsLaser in situ keratomileusis versuslaser assisted subepithelial keratectomy.

J Cataract Refract Surg.2009Oct;35(10):1774-88. doi: 10.1016/j.jcrs.2009.05.041.

27. Kamiya K, Shimizu K, Ohmoto F. The changes in corneal biomechanicalparameters after phototherapeutic keratectomy ineyes with granular corneal dystrophy. Eye. 2009Sep;23(9):1790-5. doi: 10.1038/eye.2008.373.

28. Randleman JB, Russell B, Ward MA, Thompson KP, StultingRD. Risk factors and prognosis for corneal ectasia after LASIK.Ophthalmology. 2003Feb;110(2):267-75.doi:10.1016/S01616420(02)01727-X.

29. Wittig-Silva C, Whiting M, Lamoureux E, Lindsay RG, SullivanLJ, Snibson GR. A randomized controlled trial of corneal collagencross-linking in progressive keratoconus: preliminary results.J Refract Surg. 2008Sep;24(7):S720-5.

30. Raiskup-Wolf F, Hoyer A, Spoerl E, Pillunat LE. Collagen crosslinkingwith riboflavin and ultraviolet-a light in keratoconus:long-term results. J Cataract Refract Surg. 2008May;34(5):796-801.doi: 10.1016/j.jcrs.2007.12.039.

31. Vinciguerra P, Albe E, Mahmoud MM, Trazza S, HafeziF, Roberts CJ. Intra and postoperative variation in ocular responseanalyzer parameters in keratoconic eyes after corneal crosslinking.J Refract Surg. 
2010Sep;26(9):669-76. doi: 10.3928/1081597X20100331-01.

32.Gkika M, Labiris G, Glarmoukakais A, KoutsogianniaA,KozobolisV.Evaluation of corneal hysteresis and corneal resistance factor after corneal cross-linking for keratoconus.Graefes ArchClinExp Ophthalmol.2012Apr;250(4):565-73. doi: 10.1007/s00417-011-1897-0.

33. Jafarinasab MR, Sepehr F, Javadi MA, Hashemloo A. Graftbiomechanical properties after penetrating keratoplasty versusdeep anterior lamellar keratoplasty. Curr Eye Res. 2011May;36(5):417-21. doi: $10.3109 / 02713683.2011 .556303$.
34. Hosny M, Hassaballa MAM, Shalaby A. Changes in cornealbiomechanics following different keratoplasty techniques. ClinOphthalmol2011June ;5:767-70. doi: 10.2147/OPTH.S21297

35.Abdelkader A. Influence of different keratoplasty techniques on the biomechanical properties of the cornea. ActaOphthalmol. 2013Nov;91(7):e567-72. doi: 10.1111/aos.12136.

36. AcarB T,Akdemir M Acar S Corneal biomechanical properties in eyes with no previous surgery, with previous penetrating keratoplasty and with deepanterior lamellar keratoplasty. Jpn J Ophthalmol 2013 Jan;57(1):85-9. doi: 10.1007/s10384-012-0197-5.

\section{How to cite this article?}

Nawaz S, Sofi IA, Prafulla K. Maharana, Shaveta. Comparison of biomechanical properties between post penetrating keratoplasty and deep anterior lamellar keratoplasty inkeratoconus patients using ocular response analyser. Int J Med Res Rev 2015;3(9):939-946. doi: 10.17511/ijmrr.2015.i9.175. 